\title{
Loss to follow-up amongst glaucoma patients in selected hospitals of the Limpopo Province, South Africa
}

\begin{tabular}{|c|c|}
\hline \multicolumn{2}{|c|}{$\begin{array}{l}\text { Authors: } \\
\text { Shonisani E. Tshivhase }{ }^{1} \text { (1) } \\
\text { Lunic B. Khoza } \\
\text { Takalani G. Tshitangano }\end{array}$} \\
\hline \multicolumn{2}{|c|}{$\begin{array}{l}\text { Affiliations: } \\
{ }^{1} \text { Department of Public } \\
\text { Health, Faculty of Health } \\
\text { Science, University of Venda, } \\
\text { Thohoyandou, South Africa }\end{array}$} \\
\hline \multicolumn{2}{|c|}{$\begin{array}{l}{ }^{2} \text { Department of Advanced } \\
\text { Nursing Science, Faculty of } \\
\text { Health Science, University of } \\
\text { Venda, Thohoyandou, } \\
\text { South Africa }\end{array}$} \\
\hline \multicolumn{2}{|c|}{$\begin{array}{l}\text { Corresponding author: } \\
\text { Shonisani Tshivhase, } \\
\text { shonisani.tshivhase@univen. } \\
\text { ac.za }\end{array}$} \\
\hline \multicolumn{2}{|c|}{$\begin{array}{l}\text { Dates: } \\
\text { Received: } 17 \text { Feb. } 2020 \\
\text { Accepted: } 29 \text { July } 2020 \\
\text { Published: } 28 \text { Oct. } 2020\end{array}$} \\
\hline \multicolumn{2}{|c|}{$\begin{array}{l}\text { How to cite this article: } \\
\text { Tshivhase SE, Khoza LB, } \\
\text { Tshitangano TG. Loss to } \\
\text { follow-up amongst glaucoma } \\
\text { patients in selected hospitals } \\
\text { of the Limpopo Province, } \\
\text { South Africa. Afr Vision Eye } \\
\text { Health. 2020;79(1), a559. } \\
\text { https://doi.org/10.4102/ } \\
\text { aveh.v79i1.559 }\end{array}$} \\
\hline \multicolumn{2}{|c|}{$\begin{array}{l}\text { Copyright: } \\
\text { (c) 2020. The Author(s } \\
\text { Licensee: AOSIS. This } \\
\text { is licensed under the } \\
\text { Creative Commons } \\
\text { Attribution License. }\end{array}$} \\
\hline \multicolumn{2}{|l|}{ Read online: } \\
\hline 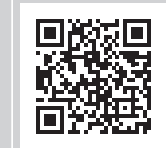 & $\begin{array}{l}\text { Scan this QR } \\
\text { code with your } \\
\text { smart phone or } \\
\text { mobile device } \\
\text { to read online. }\end{array}$ \\
\hline
\end{tabular}

Background: Glaucoma is associated with visual field loss for which elevated intraocular pressure is the primary risk factor. Proper medication adherence requires daily intake of prescribed medication for a lifetime. Non-adherence patients are at greater risk of poor outcome than adherent patients.

Aim: To identify behavioural determinants contributing to loss to follow-up amongst glaucoma patients.

Setting: The study was conducted in selected hospitals of South Africa.

Methods: A hospital-based cross-sectional study was conducted on glaucoma patients with age ranging from 18 years and above. Quantitative methods were used to collect data from purposefully selected glaucoma patients. Structured questionnaires were distributed to collect data from patients attending glaucoma clinics. The patients should have missed an appointment review at least once during the 12-month period.

Results: Amongst the 429 glaucoma patients interviewed, the majority $(79 \%, n=341)$ of the patients missed their follow-up more than once during the 12-month period. The most cited contributory barriers to poor follow-up were accessibility (26\%) followed by lack of escort and financial cost at $22 \%$ and $21 \%$, respectively. About 115 of the 429 study respondents were found to be non-adherent. The main reasons given were shortage of medication and forgetfulness at $36 \%$ and $29 \%$, respectively.

Conclusion: Accessibility and lack of escort were significant barriers to loss to follow-up. Identifying the predictors of poor follow-up can help in improving follow-up care. Therefore, patient education and support may improve adherence to glaucoma therapy.

Keywords: glaucoma; glaucoma patient; loss to follow-up; intraocular pressure; medication adherence; non-adherence.

\section{Introduction}

Glaucoma may cause vision loss and irreversible blindness if not treated. However, vision loss because of glaucoma can be prevented if detected early and properly treated. However, early identification of glaucoma and the effectiveness of screening programmes depend on the compliance with follow-up care. ${ }^{1}$ There are many reasons why glaucoma remains difficult to arrest within populations. One of the reasons is that it is asymptomatic, and thus, many people do not seek immediate medical care. ${ }^{2}$ For example, the United State of America's (USA) Preventive Service Task Force reports that evidence to support glaucoma or visual acuity screening is inadequate. More than half of the patients with abnormal screening results fail to come back for confirmatory follow-up eye examination as expected. Furthermore, glaucoma affects the quality of life through its treatment, and vision loss requires a demanding life-long multidrug regimen.,4

Loss to follow-up (LTFU) refers to patients who at one point in time were actively participating in a clinical research trial but have become lost (either by error in a computer tracking system or by being unreachable) at the point of follow-up in the trial. However, patients can become lost to follow-up for many other reasons. ${ }^{5,6}$ Participants were considered lost to follow-up if they had not reported at the referral examination (up to three different scheduled times) and failed to answer contact calls or to reschedule a missed or cancelled an appointment in up to three attempts on different days. Several studies ${ }^{5,7,8}$ have indicated that $80 \%$ of glaucoma patients do not adhere to treatment recommendations hence LTFU. Poor adherence to medication is a multifactorial issue 
with many contributing factors such as patient-centred factors, therapy-related factors, social and economic factors. ${ }^{5,9}$

Patient-related factors can negatively affect adherence to glaucoma treatment. Non-adhering patients are at greater risk of poor outcomes than adherent patients. Poor adherence can result in the ineffectiveness of treatment, whereas improvement of adherence could prevent the need to use multiple glaucoma treatment. ${ }^{10,11}$ Non-adherence to glaucoma treatment is a global problem. Several studies have been conducted worldwide regarding LTFU amongst glaucoma patients. Lifelong monitoring is an integral part of glaucoma management and lack of adequate follow-up can pose serious consequences for glaucoma patients on medical or surgical therapy. A study conducted in sub-Saharan Africa by Kyari et al. ${ }^{12}$ indicated that some patients fail to return for followup if they assumed that their treatment was no longer effective and when patients felt better and concluded that they had no need of further treatment. Long distances from hospitals and economic implications of repeated consultations and negative attitudes of healthcare workers were cited as factors contributing to LTFU.

Although glaucoma is incurable, it is treatable. The primary objective of glaucoma therapy is to prevent the progressive vision loss, disability and blindness. Regular monitoring is vital in the lowering of intraocular pressure (IOP) and maintaining vision. It is recommended that glaucoma patients are seen by the ophthalmologist at least every 6-12 months for a comprehensive eye examination according to the American Academy of Ophthalmology.7 Similarly, the South African Glaucoma Guidelines, which are in line with International Glaucoma Society Guidelines, recommend that patients with controlled glaucoma should be seen three times per year, whereas those with uncontrolled and complicated glaucoma should be seen up to six times a year. ${ }^{13}$ Therefore, the purpose of this study was to increase the understanding of reasons for LTFU amongst glaucoma patients in the selected rural hospitals of the Limpopo Province, South Africa.

\section{Research methodology Study design}

A purposive cross-sectional study was conducted on glaucoma patients who were attending follow-up clinics in order to increase the understanding of reasons for LTFU amongst glaucoma patients.

\section{Study setting}

The study was conducted in four selected hospitals of Vhembe district with patients of different ethnic cultural backgrounds. The spoken language of the population is mainly Tshivenda and Xitsonga. Vhembe is one out of the five districts of the Limpopo Province, which is one of the nine provinces in South Africa. The researcher chose to conduct the study in the selected hospitals of Vhembe district because preliminary research indicated a high rate of LTFU amongst glaucoma patients.

\section{Study design}

The study involved the use of a quantitative approach to collect data from the respondents. A cross-sectional descriptive study design was used to obtain information from the respondents.

\section{Study population}

The study population consisted of glaucoma patients who were at least 18 years and above. Participants had to be established glaucoma patients who had been under review for at least 3 years. These criteria ensured that respondents had sufficient experience of living with glaucoma and receiving treatment and follow-up care. Patients were excluded if they had ocular conditions other than glaucoma (like age-related macular degeneration, diabetic retinopathy or any other visual impairment causing disease). Respondents were also excluded if they had dementia or another isolated cognitive impairment.

\section{Sample and sampling methods}

Participants were sampled from selected hospitals with the highest rate of glaucoma loss to follow-up within the district of Vhembe. Only patients diagnosed with glaucoma were purposively sampled as they serve the best purpose of the study. The study involved both male and female glaucoma patients from the age of 18 years and above at four selected hospitals in Vhembe district of Limpopo Province. The total sample size for the study was 460 .

\section{Sample size}

The sample size was calculated using the Guidelines for Sampling by Stoker (1985) as cited by De Vos, Strydom, Fouche and Deport. ${ }^{14}$ For every population that is less than 20 , the suggested percentage is $100 \%$. In this study, for every population which was 100 and less, the researcher sampled the whole population.

\section{Data collection instrument}

The instrument was developed based on a comprehensive literature review by the first author. The instrument was drawn from other relevant studies. ${ }^{15,16,17}$ The literature review was divided into six sections. Section A covered demographic characteristics of the participants. The other five sections covered the knowledge of glaucoma disease, practices regarding glaucoma disease, attitudes regarding glaucoma disease and environmental determinants contributing to glaucoma LTFU. The questionnaire was given to a language expert who translated it into the local spoken languages. It was also translated back into English by the language expert to ensure that the original meaning was maintained. The researcher and the research assistant visited the study respondents at the eye clinic of the selected hospitals on the appointment dates. Prior to data collection, the researcher explained the purpose of the study to all respondents after obtaining an oral informed consent. The developed 
questionnaires were given to the respondents by the researcher and her research assistant. Respondents were given the questionnaires to complete on their own. However, a great number of respondents were unable to complete on their own because of illiteracy. Other respondents could not complete the questionnaire on their own because of poor vision. In the end, more than three-quarters of the respondents were assisted to complete the questionnaires. The Morisky Medication Adherence Scale (MMAS) was used as an instrument for evaluating the adherence to the glaucoma medication. ${ }^{18}$

Compliance or adherence to medication is the extent to which patients act in accordance with the prescribed interval and dose of a dosing regimen. Compliance or adherence to medication has to do with the accuracy with which a patient follows the treatment plan. ${ }^{5}$ In this study, adherence is when a patient does not miss more than two doses per week of his or her medications.

\section{Validity and reliability}

To ensure validity, the instrument was developed guided by the study objectives and literature. The instrument was also reviewed by an expert in the Department of Public Health of the University of Venda before data collection. To ensure that respondents would understand the questions, the questionnaire was translated into Tshivenda and Xitsonga by a language expert from the University of Venda's Department of Linguistics. The test-retest method was done on 46 glaucoma patients who did not form part of the study to test for clarity and appropriateness of the questions and the feasibility of the study. This was carried out by administering the questionnaire twice to the same respondents. The first set of responses was compared with the second set by calculating the correlation coefficient. The correlation coefficient was 0.85 indicating that the reliability of the instrument was high.

\section{Data analysis}

The completed questionnaires were scrutinised after data collection. The researcher used codes rather than respondents' names and checked data by frequency to identify missing or incorrect values. Those that were not properly completed were excluded and all completed questionnaires were collated and coded starting from 001 to 469. Data were then captured into the Statistical Package for Social Sciences (SPSS) software version 24 . After cleaning the data, descriptive and inferential statistics were applied to the data.

\section{Ethical considerations}

The research proposal was presented to the School Higher Degrees Committee for recommendation to the University Higher Degrees Committee for approval. The University of Venda Ethics Committee evaluated the proposal and issued an ethical clearance no SHS/18/PH/0111. Using the UHDC's approval and the ethical clearance certificate, the researcher sought permission from the Limpopo Provincial Department of Health and Vhembe District Department of Health. Furthermore, permission was also obtained from the hospital managers or CEO of all selected hospitals in Vhembe District where the study was conducted.

\section{Results}

\section{Socio-demographic factors}

The study populations comprised of 294 females (69\%) and 135 males (31\%) and $93(22 \%)$ of the respondents lived alone. Out of 460 questionnaires, 429 were satisfactorily filled by the respondents thus resulting in a response rate of $93 \%$. A total of 278 respondents, $(65 \%)$ were over 65 years old whilst 18 (4\%) were younger than 24 years. About 265 (62\%) of the respondents were Christians and 164 (38\%) practiced forms of African religion. A total of 301 (70\%) respondents did not have any formal education whilst $13(3 \%)$ had tertiary education. A total of $263(61 \%)$ respondents said they would not accept surgery to treat their glaucoma. A total of 254 (59\%) respondents indicated that they have had glaucoma disease for more than 7 years.

\section{Association between demographic factors and glaucoma awareness}

Further analysis was performed to establish the association between the age of the respondents and glaucoma knowledge and awareness. The chi-squared $p$-value at 0.05 was used. The findings showed significant association between age and awareness that glaucoma requires lifelong treatment (0.37). A large number of patients with glaucoma have no symptoms (0.19) and loss of vision because of glaucoma (0.01) was significant amongst the respondents who were 55 years and

TABLE1: Respondents' level of glaucoma knowledge ( $n=429)$.

\begin{tabular}{lcc}
\hline Statement: & \multicolumn{2}{c}{ Frequency } \\
\cline { 2 - 3 } & $n$ & $\%$ \\
\hline Perceived cause of glaucoma is: & 119 & 28 \\
Disease that runs in family/heredity & 140 & 32 \\
Eye disease that is caused by witchcraft & 170 & 40 \\
Don't know & & \\
Glaucoma is a treatable disease & 311 & 72 \\
Yes & 118 & 28 \\
No & & \\
Glaucoma patient requires lifelong treatment & 315 & 73 \\
Yes & 114 & 27 \\
No & & \\
Most patients with glaucoma have no symptoms & 180 & 42 \\
Yes & 249 & 58 \\
No & & \\
Vision loss in glaucoma is permanent & 192 & 45 \\
Yes & 237 & 55 \\
No & & \\
Glaucoma patients require follow-up care & 208 & 49 \\
Yes & 221 & 51 \\
No & & \\
If left untreated, glaucoma can lead to blindness & 194 & 45 \\
Yes & 235 & 55 \\
No & & \\
\hline
\end{tabular}


TABLE 2: Attitude and beliefs towards glaucoma disease.

\begin{tabular}{|c|c|c|c|c|}
\hline \multirow[t]{2}{*}{ Statement } & \multicolumn{2}{|c|}{ Agree } & \multicolumn{2}{|c|}{ Disagree } \\
\hline & $n$ & $\%$ & $n$ & $\%$ \\
\hline $\begin{array}{l}\text { No benefit in taking glaucoma medication } \\
\text { regularly }\end{array}$ & 115 & 26.8 & 314 & 73.1 \\
\hline $\begin{array}{l}\text { I don't want people to know that I suffer from } \\
\text { glaucoma }\end{array}$ & 252 & 58.7 & 177 & 41.2 \\
\hline $\begin{array}{l}\text { I felt very bad when I was diagnosed with } \\
\text { glaucoma }\end{array}$ & 310 & 72.6 & 119 & 27.7 \\
\hline Regular glaucoma follow-up is important & 208 & 49.0 & 208 & 49.0 \\
\hline Glaucoma is a disease of the aged & 101 & 23.5 & 318 & 74.0 \\
\hline $\begin{array}{l}\text { I feel comfortable when doctors prescribe more } \\
\text { than two eye medication to use in a day }\end{array}$ & 324 & 75.5 & 105 & 24.4 \\
\hline $\begin{array}{l}\text { I believe that using eye drops can worsen my } \\
\text { condition }\end{array}$ & 140 & 32.6 & 289 & 67.3 \\
\hline
\end{tabular}

TABLE 3: Practice regarding level of compliance $(n=429)$.

\begin{tabular}{lcc}
\hline Demographic variable & \multicolumn{2}{c}{ Frequency } \\
\cline { 2 - 3 } & $\boldsymbol{n}$ & $\mathbf{\%}$ \\
\hline Number of missed eye drops per week & 210 & 49 \\
None & 104 & 24 \\
$1-2$ & 40 & 9 \\
$3-5$ & 75 & 17 \\
More than five & & \\
Compliance & 210 & 49 \\
Yes & 219 & 51 \\
No & & \\
Reasons for non-compliance & 60 & 27.3 \\
Lack of knowledge & 56 & 25.5 \\
Forgetfulness & 40 & 18.2 \\
Denial & 35 & 15.9 \\
Misunderstanding & 28 & 12.7 \\
No specific reasons & & \\
\hline
\end{tabular}

older. The finding could imply that older patients have higher knowledge of glaucoma awareness than younger patients. However, the Pearson chi-square did not show any significance between gender, level of education and the above variables.

Out of 429 respondents, $170(40 \%)$ did not know that glaucoma is caused by heredity. On the other hand, $119(28 \%)$ respondents knew the causes of glaucoma. A total of 140 (32\%) of the respondents assumed that glaucoma disease was caused by witchcraft as shown in Table 1 .

About 311 (72\%) respondents knew that glaucoma is treatable and $315(73 \%)$ knew that glaucoma requires lifelong treatment. More than half of the respondents 235 (55\%) did not know that glaucoma can lead to blindness if left untreated (Table 1). A total of 208 (49\%) of the respondents knew that glaucoma usually requires follow-up, whereas 221 (51\%) did not know. Less than half of the respondents $180(42 \%)$ indicated that glaucoma patients had no symptoms and 249 (58\%) respondents did not know.

On the one hand $310(73 \%)$ respondents agreed that they felt very bad when they were diagnosed with glaucoma disease (Table 2). On the other hand, 119 (28\%) respondents accepted the diagnosis. Almost three quarter of the respondents, 318 (74\%) agreed that glaucoma is a disease of the aged, whereas $101(24 \%)$ disagreed. About 324 (76\%) of the respondents agreed that they felt comfortable when doctors prescribed more than two eye drops to use as opposed to 105 (24\%) who disagreed. More than half $289(67 \%)$ of the respondents agreed that using eye drops can worsen their condition compared with 140 (33\%) who disagreed.

A total of 219 (51\%) respondents had missed doses more than once per week compared with 210 (49\%) who had never missed any dose (Table 3). This study defined noncompliance as missing at least one dose of medication per week. Respondents who had a compliance rate $<100 \%$ were asked to give reasons for their failure to comply with the prescribed medication. Compliance rates were defined as good if they ranged between $95 \%$ and $100 \%$ and as poor or inadequate if they were less than $95 \%$. Inadequate knowledge $60(27 \%)$ followed by forgetfulness $56(26 \%)$ were the common specified reasons for not complying with glaucoma medication regimen. In addition, 35 (16\%) of the respondents stated that they had misunderstood dosage instructions, whilst $28(13 \%)$ could not point to specific reasons for their non-compliance.

The study revealed other socio-demographic reasons for missed clinic appointment over 12 months. Out of 341 $(79 \%)$ respondents who missed their clinic visit, 89 (26\%) missed because of lack of escort, followed by long distance and financial cost at $22 \%$ and $21 \%$, respectively. About $48.3 \%(n=207)$ of the respondents travelled more than $15 \mathrm{~km}$ to the clinic concerned.

\section{Discussions of the study findings}

There were more female $(69 \%)$ than male $(31 \%)$ respondents for this study. This disproportionate sex distribution of respondents might have been influenced by the fact that more female respondents access healthcare facilities than male respondents. Similar findings were reported by different authors who indicated high numbers of female respondents than male respondents in their studies..$^{19,20,21}$ Regarding the demographic data, ages of the respondents were found significant in relation to knowledge and awareness that glaucoma requires lifelong treatment. This is similar to the findings of Aghedo et al. ${ }^{20}$ in KwaZulu-Natal, South Africa. In an urban population of South India Durowade et al. ${ }^{21}$ revealed that there is a strong relationship between the age of the respondents and glaucoma knowledge. Respondents older than 30 years were significantly more likely to be aware of glaucoma than those below 30 years. In Australia, Curtis et al. ${ }^{22}$ reported that patients who are 65 years and older had adequate knowledge than younger patients in understanding eye drop instillation. The study further reported that older patients (above 65 years) were often happy to 'do as they are told' because of the trust they had in healthcare provider. However, this study contrasts with many other study findings by Ogbonnaya et al. ${ }^{23}$ and Mbadugha et al. ${ }^{24}$ in Lagos, Nigeria, and Prabhu et al. $^{25}$ in South India who reported that age and religion had no influence on glaucoma awareness. 
Also in contrast with the present study's findings, a study in Eastern Nepal found that there was no association amongst age, awareness and knowledge. ${ }^{26}$ Some studies further indicated that even though many of the respondents had heard about glaucoma, only a few of them had accurate understanding of glaucoma disease. ${ }^{26,27}$ However, in the present study, we observed a reduction in the higher level of knowledge of patients with increasing age. A possible explanation for this finding may be the fact that older patients forget information more easily than younger patients because of senility. Most respondents (249), that is, about 58\% in this study, reported that glaucoma disease has no symptoms. Similar results were reported by Abdull et al. ${ }^{28}$ and Altangerel et al. ${ }^{29}$ In India, Bart et al. ${ }^{30}$ stated that glaucoma is asymptomatic and painless and causes irreversible damage to the optic nerve. Similarly, Ichhpujani et al. ${ }^{31}$ indicated that damage caused by glaucoma disease to the optic nerve is reversible.

In this study, respondents exposed relatively little or a lack of knowledge about the glaucoma disease. Ichhpujani et al. ${ }^{31}$ and Altangerel et al. ${ }^{29}$ reported similar results that knowledge about glaucoma disease was inadequate amongst patients in North India and Canada respectively, as most participants claimed to be aware of glaucoma but did not understand the symptoms, risk factors and treatment. These authors further reported a startling fact of medical personnel (35\% of nurses and $20 \%$ of doctors) who did not understand that glaucoma is associated with high blood pressure in the eye and that it had an effect on the optic nerve. ${ }^{31}$ However, in Northern Nigeria, Abdull et al. ${ }^{32}$ stated that there was adequate knowledge amongst patients although patients failed to understand that the purpose of glaucoma treatment is to preserve the existing vision rather than restoring sight.

Respondents in this study revealed that they sometimes forget to administer their eye drops. Different authors Kontoh $^{11}$ and $\mathrm{Ajayi}^{33}$ and Blondeau et al. ${ }^{34}$ similarly found that forgetfulness to medications contributes to nonadherence. Olthoff et $\mathrm{al}^{35}$ and Tsai ${ }^{36}$ stated that glaucoma patients forgot their medications because there is no direct advantage from the eye drops and no immediate disability from the disease. Also, patients who failed to accept their glaucoma disease and the use of treatment for life tend to forget easily as attested by Tsai. ${ }^{36}$ The findings concur with the study results by Newman-casey et al. ${ }^{5}$ who reported that $62 \%$ of the patients cited forgetfulness as their number one barrier with both non-adherent and adherent patients.

This study revealed that some respondents had a negative attitude towards glaucoma treatment and management. Most respondents (73\%) felt very bad when they were diagnosed with glaucoma and did not want other people to know about their disease. This is attributed to the fact that respondents are afraid of going blind and are worried about living with a chronic condition. Some respondents felt uncertain about their future because of glaucoma disease. Similar results were reported in a South African study conducted in KwaZulu-Natal with 95\% patients showing a negative attitude towards their glaucoma diagnosis but on the other hand feeling happy with the use of their eye drops..$^{20}$ In this study, more than half of the study respondents were not aware that they should do regular glaucoma follow-up. This is attributed to the ineffective information given to some of the patients. Similar results were attested by Demirtaş et $a .^{37}$ who mentioned that glaucoma patients were not aware about the importance of regular eye examination. However, the study by Thompson et al. ${ }^{17}$ reported that other patients believed in the importance of follow-up even when there is no visible change in their vision after using the medications.

This study also revealed that some respondents' poor practice contributed to non-compliance with the treatment and management of their condition leading to LTFU. The study showed that 219 (51\%) of the respondents were not compliant with treatment and management. Patients on single eye drop adhered more to their glaucoma medication than those on multiple eye drops. Stryker et al. ${ }^{38}$ and Castel et al. ${ }^{39}$ stated that adherent patients believed that medications prevent disease progression and maintain vision. The study further mentioned about the benefits of using eye drops regularly. However, some of the study respondents indicated that they sometimes use traditional eye medications to treat glaucoma disease and others consult their spiritual healers. Some of the respondents perceived that glaucoma is caused by witchcraft or evil spirit. De-gaulle et al. ${ }^{40}$ reported similar findings in their study stating that glaucoma patients preferred alternative eye care service such as traditional healers and also preferred local pharmaceutical shops than visiting an ophthalmologist or optometrist. Similar studies conducted by Abdull et al. ${ }^{28}$ reported that traditional healers were the most respected and trusted people in some of the African countries. The study further indicated that environmental factors greatly contributed to respondents' missing clinic visits resulting in non-compliance. Factors such as financial means, no escort to accompany respondents and long queues at the clinics were raised.

The study showed consistency with those conducted by Sun et al. $^{41}$ in China and Radhakrishnan et al. ${ }^{42}$ in India who reported that patients had failed to attend their follow-up and travelling difficulty were noted as reasons for nonattendance. Ehiemua ${ }^{43}$ also obtained similar findings in Namibia. Several researchers found that patients spend many hours waiting to access care at every point because of reasons such as hospital staffs' inability to retrieve patients' files, patients queuing for a long time, difficulty in scheduling the appointment making use of an interpreter during consultation and patients from different clinics made to attend at a single point. ${ }^{44,45,46}$ Similar studies conducted by Momoh et al. $^{46}$ in Southern Nigeria and Abdull ${ }^{44}$ in SouthEast Nigeria discovered that patients residing more than $50 \mathrm{~km}$ from the health facility showed poor follow-up than respondents living nearer to health facilities. In California (United States [US]) and Philadelphia (US), researchers 
reported that glaucoma patients expressed financial barriers and lack of escort to access healthcare services as attributing to LTFU. Thompson et al. ${ }^{17}$, Kim et al. ${ }^{47}$, Lee et al. ${ }^{48}$ and Landers et al. ${ }^{49}$ pointed out that rural healthcare is characterised by challenges such as longer commuting distances, which lead to slower access to critical care during emergencies. One study shows that travel and financial cost are intrinsically linked and it is so difficult to separate them as distinct components. ${ }^{38}$

\section{Limitations}

The study was only conducted in selected hospitals of Vhembe district. Therefore, the results cannot be generalised to the rest of Limpopo Province. Moreover, the study was restricted to patients with established glaucoma presenting themselves at hospitals that only provide glaucoma services. Further research work should be done on glaucoma patients using qualitative methods to try and get detailed information regarding LTFU.

\section{Conclusion}

Our study shows that non-adherence to scheduled followup appointment amongst glaucoma patients in rural hospitals is prevalent. Patients outlined various reasons that contributed to their glaucoma LTFU. The reasons included inadequate knowledge regarding the disease itself, perception that compliance with medications and follow-up are less important, forgetfulness, financial difficulties, lack of an escort to the clinic, travel distance from home to the clinic exceeding more than $15 \mathrm{~km}$, long hospital queues and also the belief that glaucoma is caused by witchcraft or evil spirit. Similarly, the study concurs with other studies that were conducted mostly in subSaharan Africa. Therefore, appropriate measures need to be taken to strengthen eye care follow-up amongst glaucoma patients.

\section{Recommendations}

Patients should be informed about the advantages and disadvantages of glaucoma LTFU. Family members and community should be educated on eye conditions such as glaucoma so that they should be involved in the care and offer support. Vhembe District Department of Health should provide one or more mobile clinic vans for easy access to most glaucoma patients who stay far from the health facilities. Eye healthcare practitioners should be provided with training on motivational interviewing to equip them with skills to motivate glaucoma patients to remain in care. Campaigns to enhance public eye awareness on glaucoma diseases should be launched to improve the effectiveness of health promotion and prevent unnecessary blindness. All this could significantly improve the quality of life for these people and their families, whilst at the same time reducing national expenditure by healthcare services and increasing productivity in the economy of the country.

\section{Acknowledgements}

The authors thank all the participants who participated in the study and also the University of Venda Research and Innovation for funding this project.

\section{Competing interests}

The authors have declared that no competing interests exist.

\section{Authors' contributions}

All the authors have contributed equally to this work.

\section{Funding information}

The research received no specific grant from any funding agency in the public, commercial or not-for-profit sectors.

\section{Data availability statement}

Data have been saved by the principal author and are available upon request.

\section{Disclaimer}

The views and opinions expressed in this article are those of the authors and do not necessarily reflect the official policy or position of any affiliated agency of the authors.

\section{References}

1. Rumelt $S$, Schreiber $S$. Why do patients with controlled glaucoma continue to lose their vision? Causes and coping with visual impairment and blindness. London: IntechOpen . 2018;19:23-32.

2. Susanna R, De Moraes CG, Cioffi GA, Ritch R. Why do people (still) go blind from glaucoma? Transl Vis Sci Technol. 2015;4(2):1. https://doi.org/10.1167/tvst.4.2.1

3. Quaranta L, Riva I, Gerardi C, Oddone F, Floriano I, Konstas AG. Quality of life in glaucoma: A review of the literature. Adv Ther. 2016;33(6):959-981. https://doi. org/10.1007/s12325-016-0333-6

4. Zheng CX, Hu WD, Tran J, et al. Barriers to receiving follow-up eye care and detection of non-glaucomatous ocular pathology in the Philadelphia Glaucoma Detection and Treatment Project. I Community Health. 2016:41(2):359-367. https://doi.org/10.1007/s10900-015-0104-3

5. Newman-Casey PA, Robin AL, Blachley $T$, et al. The most common barriers to glaucoma medication adherence: A cross-sectional survey. Ophthalmology. 2015;122(7):1308-1316. https://doi.org/10.1016/j.ophtha.2015.03.026

6. Dettori JR. Loss to follow-up. Evid Based Spine-Care J. 2011;2(01):7-10. https:// doi.org/10.1055/s-0030-1267080

7. Fudemberg SJ, Lee $B$, Waisbourd $M$, et al. Factors contributing to nonadherence to follow-up appointments in a resident glaucoma clinic versus primary eye care clinic. Patient Prefer Adherence. 2016;2016(10):19. https://doi.org/10.2147/PPA.S89336

8. Cate H, Bhattacharya D, Clark A, Holland R, Broadway DC. Patterns of adherence behaviour for patients with glaucoma. Eye. 2013;27(4):545-553. https://doi. org/10.1038/eye.2012.294

9. Kulkarni SV, Damji KF, Buys YM. Medical management of primary open-angle glaucoma: Best practices associated with enhanced patient compliance and persistency. Patient Prefer Adherence. 2008;2008(2):303. https://doi.org/ 10.2147/PPA.S4163

10. Njenga LN. Determinants of non-adherence to long term therapy with prescription medicines in adult patients attending medical outpatient clinic at Mbagathi Hospital [Doctoral dissertation]. Brarvi: Kenyatta University.

11. Kontoh DO. Factors influencing non-adherence to topical anti-glaucoma medications among patients attending Crystal Eye Clinic, Adenta, ARCA Academic Ltd [Doctoral dissertation]. University of Ghana.

12. Kyari F, Adekoya B, Abdull MM, Mohammed AS, Garba F. The current status of glaucoma and glaucoma care in sub-Saharan Africa. Asia-Pacific J Ophthalmol. 2018;7(6):375-386.

13. Tham YC, Li X, Wong TY, Quigley HA, Aung T, Cheng CY. Global prevalence of glaucoma and projections of glaucoma burden through 2040: A systematic review and meta-analysis. Ophthalmology. 2014;121(11):2081-2090. https://doi. org/10.1016/j.ophtha.2014.05.013

14. De Vos AS, Delport CS, Fouché CB, Strydom H. Research at grass roots: A primer for the social science and human professions. Pretoria: Van Schaik Publishers; 2011. 
15. Sathyamangalam RV, Paul PG, George R, et al. Determinants of glaucoma awareness and knowledge in urban Chennai. Indian J Ophthalmol. 2009·57(5):355. https://doi.org/10.4103/0301-4738.55073

16. Welge-Lussen $U$, Weise $S$, Alice LY. Assessing the adherence behavior of glaucoma patients to topical eye drops. Patient Prefer Adherence. 2015;2015(9):17. https:// doi.org/10.2147/PPA.S69943

17. Thompson AC, Thompson MO, Young DL, et al.. Barriers to follow-up and strategies to improve adherence to appointments for care of chronic eye diseases. Investig Ophthalmol Vis Sci. 2015;56(8):4324-4331. https://doi.org/10.1167/iovs.15-16444

18. De Oliveira-Filho AD, Morisky DE, Neves SJ, Costa FA, De Lyra Junior DP. The 8-item Morisky Medication Adherence Scale: Validation of a Brazilian-Portuguese version in hypertensive adults. Res Soc Admin Pharm. 2014;10(3):554-561. https://doi.org/10.1016/j.sapharm.2013.10.006

19. Jin YP, Miller G, Lin K, Trope GE. Glaucoma knowledge in a black community in Toronto. Int J Ophthalmol Eye Res. 2014;2(5):59-64. https://doi.org/10.19070/ 2332-290X-1400011

20. Aghedo AV, Tlou B, Mahomed S. Knowledge, attitudes and self-care practices of patients with glaucoma in uThungulu in KwaZulu-Natal. Afr Vis Eye Health 2018;77(1):1-6. https://doi.org/10.4102/aveh.v77i1.442

21. Durowade KA, Babatunde OA, Salaudeen AG, Musa OI, Bolarinwa OA, Anyaike C. Knowledge and risk factors for glaucoma among adults in a rural Community of Kwara State, North-Central Nigeria. TAF Prev Med Bull. 2014;13(5):375-380. https://doi.org/10.5455/pmb.1-1379622282

22. Curtis JR, Xi J, Westfall AO, et al. Improving the prediction of medication compliance: The example of bisphosphonates for osteoporosis. Med Care. 2009;47(3):334. https://doi.org/10.1097/MLR.0b013e31818afa1c

23. Ogbonnaya CE, Ogbonnaya LU, Okoye O, Kizor-Akaraiwe N. Glaucoma awareness and knowledge, and attitude to screening, in a rural community in Ebonyi State, Nigeria. Open J Ophthalmol. 2016;6(2):119-127. https://doi.org/10.4236/ojoph. 2016.62017

24. Mbadugha CA, Onakoya AO. The awareness, perceptions and experiences of primary open angle glaucoma patients in Lagos Nigeria. Sci Rep. 2014;4(1):1-6. https://doi.org/10.1038/srep07585

25. Prabhu M, Patil SH, Kangokar PC. Glaucoma awareness and knowledge in a tertiary care hospital in a tier-2 city in South India. J Sci Soc. 2013;40(1):3. https:// doi.org/10.4103/0974-5009.109674

26. Atalay K, Kirgiz A, Aşik Ş. Awareness and knowledge of glaucoma among healthcare workers and patients in a big city of Turkey. Glokom-Katarakt. 2019;14(3):123-128.

27. Shakya-Vaidya S, Povlsen L, Shrestha B, Grjibovski AM, Krettek A. Understanding and living with glaucoma and non-communicable diseases like hypertension and
diabetes in the Jhaukhel-Duwakot Health Demographic Surveillance Site: A diabetes in the Jhaukhel-Duwakot Health Demographic Surveillance Site: A
qualitative study from Nepal. Glob Health Act. 2014;7(1):25358. https://doi. qualitative study from Nepal
org/10.3402/gha.v7.25358

28. Abdull MM, Gilbert CC, Evans J. Primary open angle glaucoma in northern Nigeria: Stage at presentation and acceptance of treatment. BMC Ophthalmol. 2015;15(1):111. https://doi.org/10.1186/s12886-015-0097-9

29. Altangerel $U$, Nallamshetty HS, Uhler T, et al. Knowledge about glaucoma and barriers to follow-up care in a community glaucoma screening program. Can J Ophthalmol. 2009;44(1):66-69. https://doi.org/10.3129/i08-175

30. Batra R, Tailor R, Mohamed S. Ocular surface disease exacerbated glaucoma: Optimizing the ocular surface improves intraocular pressure control. J Glaucoma. 2014;23(1):56-60. https://doi.org/10.1097/IJG.0b013e318264cd68

31. Ichhpujani P, Bhartiya S, Kataria M, Topiwala P. Knowledge, attitudes and self-care practices associated with glaucoma among hospital personnel in a tertiary Care Center in North India. J Curr Glaucoma Prac. 2012;6(3):108. https://doi. org/10.5005/jp-journals-10008-1116
32. Abdull MM, Chandler C, Gilbert C. Glaucoma, "the silent thief of sight": Patients' perspectives and health seeking behaviour in Bauchi, northern Nigeria. BMC Ophthalmol. 20161;16(1):44. https://doi.org/10.1186/s12886-016-0220-6

33. Ajayi IA, Omotoye OJ, Ajite KO, Fadamiro CO, Ajayi EA. Self medication practices among patients seen in A suburban tertiary eye care centre in Nigeria. Asian J Med Sci. 2014;5(2):85-90. https://doi.org/10.3126/ajms.v5i2.8452

34. Blondeau P, Esper P, Mazerolle É. An information session for glaucoma patients. Can J Ophthalmol. 2007;42(6):816-820. https://doi.org/10.3129/i07-154

35. Olthoff CM, Hoevenaars JG, Van den Borne BW, Webers CA, Schouten JS Prevalence and determinants of non-adherence to topical hypotensive treatment in Dutch glaucoma patients. Graefe's Arch Clin Exp Ophthalmol. 2009;247(2):235. https://doi.org/10.1007/s00417-008-0944-y

36. Tsai JC. A comprehensive perspective on patient adherence to topical glaucoma therapy. Ophthalmology. 2009;116(11):S30-S36. https://doi.org/10.4274/tjo.26576

37. Demirtaş Z, Dağtekin G, Önsüz MF, Soysal A, Yıldırım N, Metintaş S. Validity and reliability of the glaucoma knowledge level questionnaire. Turkish $\mathrm{j}$ Ophthalmol. 2018;48(3):115. https://doi.org/10.4274/tjo.26576

38. Stryker JE, Beck AD, Primo SA, Echt KV, Bundy L, Pretorius GC, Glanz K. An exploratory study of factors influencing glaucoma treatment adherence. J Glaucoma. 2010 Jan;19(1):66. https://doi.org/10.1097/IJG.0b013e31819c4679

39. Cohen Castel O, Keinan-Boker L, Geyer O, Milman U, Karkabi K. Factors associated with adherence to glaucoma pharmacotherapy in the primary care setting. Fam Prac. 2014;31(4):453-461. https://doi.org/10.1093/fampra/cmu031

40. De-Gaulle VF, Dako-Gyeke P. Glaucoma awareness, knowledge, perception of risk and eye screening behaviour among residents of Abokobi, Ghana. BMC Ophthalmol. 2016;16(1):1-7. https://doi.org/10.1186/s12886-016-0376-0

41. Sun J, Zhou X, Kang Y, et al. Prevalence and risk factors for primary open-angle glaucoma in a rural northeast China population: A population-based survey in Bin County, Harbin. Eye. 2012;26(2):283-291. https://doi.org/10.1038/eye. 2011.243

42. Radhakrishnan M, Venkatesh R, Valaguru V, Frick KD. Economic and social factors that influence households not willing to undergo cataract surgery. Indian Ophthalmol. 2015;63(7):594. https://doi.org/10.4103/0301-4738.167116

43. Ehiemua UR. Reasons for poor adherence to Antiretroviral Therapy (ART) by young female (15-24 years) HIV/AIDS patients in Oshakati district [Doctoral dissertation]. Stellenbosch: Stellenbosch University

44. Abdull M. Patients and glaucoma: what are the challenges? Community Eye Health. 2012;25(79-80):44. https://doi.org/10.2147/OPTH.S37145

45. Adio AO, Onua AA. Economic burden of glaucoma in Rivers State, Nigeria. Clin Ophthalmol (Auckland, NZ). 2012;2012(6):2023. https://doi.org/10.2147/OPTH. S37145

46. Momoh RO, Bunce C, Oko-oboh GA, Gilbert CE. Advanced glaucoma at presentation is associated with poor follow-up among glaucoma patients attending a tertiary eye facility in Southern Nigeria. Ophthalmic Epidemiol. 2018;25(3):266-272. https://doi.org/10.1080/09286586.2018.1424345

47. Kim CY, Park KH, Ahn J, et al. Treatment patterns and medication adherence of patients with glaucoma in South Korea. Br J Ophthalmol. 2017;101(6):801-807. https://doi.org/10.1136/bjophthalmol-2016-308505

48. Lee BW, Sathyan P, John RK, Singh K, Robin AL. Predictors of and barriers associated with poor follow-up in patients with glaucoma in South India. Arch Ophthalmol. 2008;126(10):1448-1454. https://doi.org/10.1001/archopht.126.10.1448

49. Landers J, Henderson T, Craig J. The prevalence of glaucoma in indigenous Australians within Central Australia: The Central Australian Ocular Health Study. Br J Ophthalmol. 2012;96(2):162-166. https://doi.org/10.1136/ bjo.2010.196642 